\title{
Fibronectin fragments modulate monocyte VLA-5 expression and monocyte migration
}

\author{
JoAnn Trial, ${ }^{1,2}$ Robert E. Baughn, ${ }^{3,4}$ James N. Wygant, ${ }^{5}$ \\ Bradley W. McIntyre, ${ }^{5}$ Holly H. Birdsall, ${ }^{1,4,6}$ Keith A. Youker, ${ }^{2,7}$ \\ Alida Evans, 2,7 Mark L. Entman, 2,7 and Roger D. Rossen ${ }^{1,2,4}$ \\ ${ }^{1}$ Immunology Research Laboratory and the Research Center for AIDS and HIV-Related Infections, \\ Houston Veterans Affairs Medical Center, \\ ${ }^{2}$ Department of Medicine, Baylor College of Medicine, \\ ${ }^{3}$ Syphilis Research Laboratory, Houston Veterans Affairs Medical Center,and \\ ${ }^{4}$ Department of Microbiology and Immunology, Baylor College of Medicine, Houston, Texas 77030, USA \\ ${ }^{5}$ Department of Immunology, University of Texas M.D. Anderson Cancer Center, Houston, Texas 77054, USA \\ ${ }^{6}$ Department of Otorhinolaryngology, Baylor College of Medicine, and \\ ${ }^{7}$ Section of Cardiovascular Sciences and the DeBakey Heart Center, Methodist Hospital, Houston, Texas 77030, USA
}

Address correspondence to: JoAnn Trial, Houston Veterans Affairs Medical Center, Building 109, 2002 Holcombe Boulevard, Houston, Texas 77030, USA. Phone: (713) 791-1414 ext. 5877; Fax: (713) 790-9141; E-mail: jtrial@bcm.tmc.edu.

Received for publication August 5, 1998, and accepted in revised form July 8, 1999.

\begin{abstract}
To identify the mechanisms that cause monocyte localization in infarcted myocardium, we studied the impact of ischemia-reperfusion injury on the surface expression and function of the monocyte fibronectin (FN) receptor VLA-5 $\left(\alpha_{5} \beta_{1}\right.$ integrin, CD49e/CD29). Myocardial infarction was associated with the release of FN fragments into cardiac extracellular fluids. Incubating monocytes with postreperfusion cardiac lymph that contained these FN fragments selectively reduced expression of VLA-5, an effect suppressed by specific immunoadsorption of the fragments. Treating monocytes with purified, 120-kDa cell-binding FN fragments (FN120) likewise decreased VLA-5 expression, and did so by inducing a serine proteinase-dependent proteolysis of this $\beta_{1}$ integrin. We postulated that changes in VLA-5 expression, which were induced by interactions with cell-binding FN fragments, may alter monocyte migration into tissue $\mathrm{FN}$, a prominent component of the cardiac extracellular matrix. Support for this hypothesis came from experiments showing that FN120 treatment significantly reduced both spontaneous and MCP-1-induced monocyte migration on an FN-impregnated collagen matrix. In vivo, it is likely that contact with cell-binding FN fragments also modulates VLA-5/FN adhesive interactions, and this causes monocytes to accumulate at sites where the fragment concentration is sufficient to ensure proteolytic degradation of VLA-5.
\end{abstract}

J. Clin. Invest. 104:419-430 (1999).

\section{Introduction}

Leukocytes promptly infiltrate formerly ischemic myocardium upon reperfusion (1). Although this inflammatory response may injure myocardial cells that would otherwise survive the ischemic episode (2), it also has a reparative function $(3,4)$. Suppression of this host response impairs scar formation and may result in the formation of ventricular aneurysms (5-8). Neutrophils initially predominate after reperfusion $(9,10)$, but the proportion of monocytes in these infiltrates increases progressively with time (11). These tissue-infiltrating monocytes are most directly implicated in the repair process (12-14). Monocyte-derived macrophages provide agents such as PDGF (15), TNF, acidic fibroblast growth factor (12-14), TGF- $\beta$ (16-18), and other factors that help to promote the formation of new blood vessels, fibroblast proliferation, and the production of collagen and other extracellular matrix proteins (19).

The sequential release of 3 chemoattractive agents C5a, TGF- $\beta_{1}$, and monocyte chemoattractant protein- 1 (MCP-1) - by reperfused myocardium ensures that monocytes are attracted to the damaged heart tissue for up to 24 hours after blood flow is reestablished (11).
Although these agents can induce monocyte migration across endothelial barriers (11), it is not clear what causes their accumulation in sites containing infarcted myocardium. The present study identifies a novel mechanism for regulating monocyte trafficking in injured tissues. Specifically, our results show that monocyte-tissue matrix interactions are partially regulated by modulating the quantity of the fibronectin (FN) receptor VLA-5 (CD49e/CD29) displayed on the monocyte surface (20).

The background for this research was provided by previous studies that examined the inflammatory response effects on tissue $\mathrm{FN}(21,22)$. These studies suggested that inflammation produces proteolytic enzymes that cleave FN, thereby releasing FN fragments containing cryptic binding sites for VLA-5 (23). Within a narrow dose range, these FN fragments stimulate monocyte chemokinesis (24) and chemotaxis (21, 23). These studies also reported that high concentrations of FN fragments are not chemotactic (23). Indeed, they may actually interfere with FN-dependent adhesive interactions (25).

In our study, reperfusion of ischemic myocardium released diverse FN fragments into cardiac extracellular 
fluids. Cell-binding FN fragments released under these circumstances induced the proteolysis of monocyte cellsurface VLA-5. This process appeared to be mediated by serine proteases activated in the course of the response to myocardial injury.

\section{Methods}

Reagents. Preservative-free heparin was obtained from Apothecon (Princeton, New Jersey, USA). BSA, LPS (Escherichia coli serotype 0127:B8), glucose, 2-deoxyglucose, sodium azide, ovalbumin, $\mathrm{CdCl}_{2}$, bestatin, 1,10phenanthroline, PMSF, and EGTA were purchased from Sigma Chemical Co. (St. Louis, Missouri, USA). Disodium EDTA was purchased from Fisher Scientific Co. (Pittsburgh, Pennsylvania, USA). Trasylol (aprotinin injection) was purchased from Miles Inc. (Elkhart, Indiana, USA). Native human plasma FN, the 120- and 40$\mathrm{kDa}$ fragments of human plasma FN (FN120 and FN40, respectively), gly-arg-gly-asp-asn-pro (GRGDNP) peptide, gly-arg-gly-glu-ser-pro (GRGESP) peptide, Dulbecco's 10× PBS (DPBS), HBSS, and RPMI-1640 were all purchased from GIBCO BRL (Gaithersburg, Maryland, USA). FBS was purchased from HyClone Laboratories (Logan, Utah, USA). U937 cells were from the American Type Culture Collection (Rockville, Maryland, USA). Endotoxin testing was performed using the Limulus amebocyte assay (Associates of Cape Cod, Falmouth, Massachusetts, USA), which can detect as little as $0.03 \mathrm{U} / \mathrm{mL}$.

Animal experiments. The canine model has been described previously (11, 26-28). Briefly, under general anesthesia, a hydraulic occluder is placed proximal to the first branch of the circumflex coronary artery, and the major cardiac lymph duct is cannulated. Three days later, again under general anesthesia, the occluder is inflated for 1 hour and then deflated to permit reperfusion. Ischemia is monitored by electrocardiography, by a Doppler flow probe previously implanted distal to the occluder, and by estimating regional myocardial blood flow (measured using the reference sample method with radiolabeled microspheres injected into the arterial circulation) (28). Significant ischemia was defined as a more than $80 \%$ reduction in regional myocardial blood flow when compared with the preocclusion value; infarction was generally evident in segments where regional myocardial blood flow was reduced to this extent (11). Some dogs do not develop significant ischemia, presumably because of collateral circulation. These dogs served as nonischemic controls.

Blood and lymph processing. Blood and cardiac lymph were collected into polypropylene tubes containing preservative-free heparin $(10 \mathrm{U} / \mathrm{mL})$ for immunofluorescence and flow cytometric studies. For immunoblotting, collection tubes contained aprotinin (200 kallikrein-inhibitor units/mL) PMSF (1 mM), and EDTA (0.15\%). To study the effects of lymph FN and its fragments on monocyte VLA-5 expression, lymph - collected 5 hours after reperfusion from 3 dogs - was collected without protease inhibitors. All lymph samples were promptly centrifuged to remove cells, and then were flash frozen and stored in liquid nitrogen. To remove FN selectively from lymph samples, $75-\mu \mathrm{L}$ aliquots were passed sequentially 4 times (for $>1$ hour each) into the wells of an Immobilon 2 plate
(Dynatech Laboratories Inc., Chantilly, Virginia, USA) that had been coated with a 1:500 dilution of rabbit antihuman FN or, as a control, with normal rabbit serum. PAGE and Western blot analysis documented that this immunoadsorption selectively depleted these samples of $\mathrm{FN}$ and its fragments.

Antibodies. We used the following mAb's: CD49e MAB1956 (clone P1D6) and MAB1986 (clone CLB-705) (Chemicon International, Temecula, California, USA); CD49e (clone 16) (Becton Dickinson and Co., Franklin Lakes, New Jersey, USA); CD49e (clone SAM-1), CD49d (clone HP2.1), CD49f (clone GoH3), and CD14 (clone 116, phycoerythrin conjugated) (Immunotech, Westbrook, Maine, USA); CD14 (clone TÜK4, phycoerythrin conjugated) from DAKO A/S (Glostrup, Denmark); and integrin $\beta_{1}$ chain (clone 33B6) from B. McIntyre (M.D. Anderson Cancer Center, Houston, Texas, USA). CD11b was grown as a culture supernatant of the OKM1 hybridoma clone, obtained from the American Type Culture Collection; AM3K (a marker associated with monocytes/macrophages) was a gift from K. Takahashi (Kumamoto University, Kumamoto, Japan ) $(29,30)$. Control mouse IgGs were obtained from Coulter Electronics Ltd. (Hialeah, Florida, USA). Affinity-purified, fluorescein-conjugated sheep $\mathrm{F}\left(\mathrm{ab}^{\prime}\right)_{2}$ anti-mouse IgG (whole molecule) with no crossreactivity to human immunoglobulin came from Organon Teknika Corp. (West Chester, Pennsylvania, USA). Rabbit anti-human FN was obtained from Calbiochem -Novabiochem Corp. (San Diego, California, USA). Horseradish peroxidase-conjugated goat antibodies to the IgG of other species were obtained from Sigma Chemical Co. AB1937 (a rabbit antiserum against the $\beta_{1}$ chain), AB1950 (a goat antiserum against $\alpha_{5} / \beta_{1}$ ), and AB1928P (an affinity-purified rabbit antibody against a peptide representing the COOH-terminal 23 amino acids of the cytoplasmic domain of human $\alpha_{5}$ ) were obtained from Chemicon International. A search of GenBank/EMBL/DDBJ revealed that this 23-amino acid peptide, KRSLPYGTAMEKAQLKPPATSDA, is not found in other domains of VLA-5, nor is it found in other known protein sequences.

Immunohistology. Tissue samples were processed for histological examination as described previously $(11,31)$. Tissue samples were selected for analysis based on measurements showing that their regional myocardial blood flow during occlusion was less than $20 \%$ of the preocclusion measurement; control tissues retained the same preocclusion blood flow throughout the experiment. Fixed, paraffin-blocked tissues were sectioned serially at 2-4 $\mu \mathrm{m}$. These were stained with routine reagents or deparaffinated, and then hydrated in PBS and treated alternatively with the AM-3K anti-monocyte/macrophage $\mathrm{mAb}$ (30) and VLA-5-specific antibodies.

To identify the conditions in which $\mathrm{AM}-3 \mathrm{~K}^{+}$cells retain the ability to react with anti-VLA-5, sections were first incubated with AM-3K and then with an alkaline phosphatase-conjugated secondary antibody and alcoholsoluble fast red substrate. Then we incubated these same tissue sections with the rabbit anti- $\alpha_{5}$ antibody (AB1928P; Chemicon International) followed by peroxidase-conjugated sheep anti-rabbit immunoglobulin and an alcohol-insoluble orange substrate (32). Sections were then counterstained with hematoxylin. After capturing 
the images of the dual-stained cells in these sections, the coverslips were removed, and the fast red chromogen associated with the AM-3K mAb was removed with absolute alcohol. The same sections were photographed again to determine whether cells stained with AM-3K retained any orange stain, indicative of a reaction with the VLA-5-specific antibody.

Immunofluorescence. Two sources of phycoerythrin-conjugated anti-CD14 were used to identify monocytes: clone 116 for human cells, and TÜK4 for canine monocytes. Leukocytes were analyzed by flow cytometry on an Epics Profile I (Coulter Electronics Ltd.) the day of the experiment. The fluorescence intensity $\log$ values obtained from cells stained with control isotype mouse IgG were subtracted from each sample stained with specific antibody. Quantitative flow cytometry was performed using the Quantum Simply Cellular Microbeads kit (Sigma Chemical Co.), which contains 4 bead populations that each bind different predetermined numbers of antibodies per bead. After excitation, the light emitted by these beads provides a standard curve that allows measurement of instrument performance and, by interpolation, the number of molecules bound per cell in an unknown sample.

Cell preparation. Heparinized human blood, which was obtained from healthy donors under protocols approved by the institutional review boards of Baylor College of Medicine and the Houston Veterans Affairs Medical Center, was centrifuged through Ficoll-Hypaque gradients (lymphocyte separation medium; Organon Tekni$\mathrm{ka}$ ) to harvest mononuclear leukocytes (MNLs). We also isolated MNLs enriched for monocytes ( $84 \pm 2 \%$ monocytes with $10 \%$ lymphocytes and $<2 \%$ granulocytes) by countercurrent flow elutriation. Monocytes elutriated at $4^{\circ} \mathrm{C}$ become activated upon rewarming (33); as a result, elutriated cells express very little VLA-5 when subsequently cultured for 30 minutes at $37^{\circ} \mathrm{C}$. Therefore, elutriated cells were routinely cultured overnight at $37^{\circ} \mathrm{C}$ in polypropylene tubes (to prevent adherence), after which they reexpressed normal levels of VLA-5.

Effect of FN fragments on VLA-5. Lyophilized FN fragments were dissolved in pyrogen-free DPBS and added to heparinized whole blood at various concentrations. After dose-response and kinetic analyses were completed, we commonly used $0.5 \mathrm{nmol}(60 \mu \mathrm{g})$ of FN120 per $10^{6}$ cells for investigating the effects of cell-binding FN fragments on suspensions of monocytes or U937 cells. For matrix interaction assays, cells were washed after treatment with FN fragments. All incubations of blood, isolated MNLs or U937 cells with FN fragments, cardiac lymph, or polymerized collagen matrices were carried out at $37^{\circ} \mathrm{C}$ in humidified air containing $5 \% \mathrm{CO}_{2}$.

Matrix interaction assay. We allowed $500 \mu \mathrm{L}$ of $50 \%$ soluble collagen (Vitrogen 100; Collagen Corp., Palo Alto, California, USA) to polymerize in each well of a 24-well plate (Corning-Costar Corp., Acton, Massachusetts, USA). We incorporated $20 \mu \mathrm{g} / \mathrm{mL}$ native $\mathrm{FN}$ or an equal concentration of laminin (GIBCO BRL) into some of the collagen pads. Alternatively, collagen with or without $20 \mu \mathrm{g} / \mathrm{mL}$ of FN was polymerized in tissue culture inserts floored with $0.4-\mu \mathrm{m}$ pore filters. MNLs or elutriated monocytes were treated with $2 \mu \mathrm{M}$ FN120 or
DPBS for 90 minutes at $37^{\circ} \mathrm{C}$, and the fluorescent supravital dye 5-chloromethylfluorescein diacetate (CellTracker Green; Molecular Probes Inc., Eugene, Oregon, USA) was added for the last 30 minutes. The MNLs were washed once with DPBS and allowed to migrate into the collagen at $37^{\circ} \mathrm{C}$, either without stimulus or in response to $120 \mathrm{ng} / \mathrm{mL}$ of recombinant MCP-1 (R\&D Systems Inc., Minneapolis, Minnesota, USA) placed in the chamber below the collagen pad as described (34). After 4 hours, the surface of the pad was washed to remove nonadherent MNLs. The polymerized collagen was then dissolved with collagenase (34); cells that had

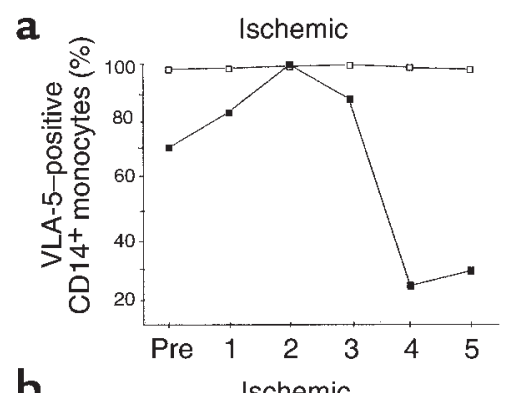

b

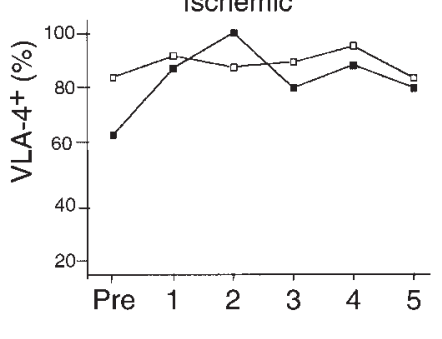

C

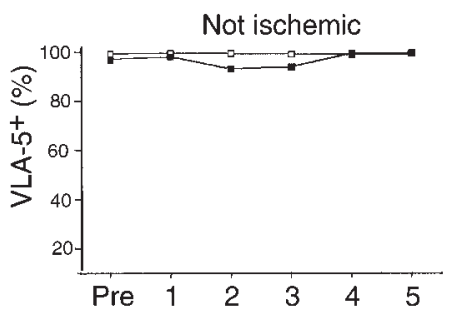

d

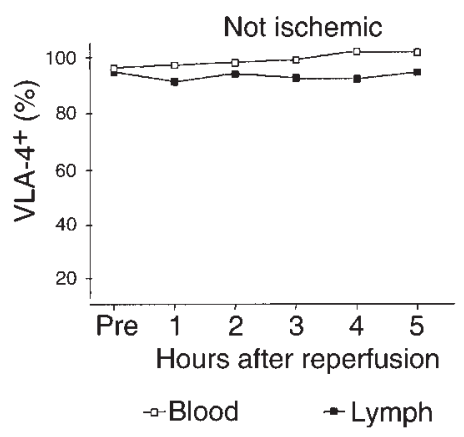

Figure 1

At 3-5 hours after reperfusion, few monocytes in cardiac extracellular fluids expressed VLA-5. The percentage of CD14+ blood and lymph monocytes bearing VLA-5 ( $\mathbf{a}$ and $\mathbf{c}$ ) or VLA-4 ( $\mathbf{b}$ and $\mathbf{d}$ ) were measured in a dog with significant myocardial ischemia and in a dog without ischemia (c and $\mathbf{d}$ ). Open squares represent data from blood, and filled squares represent data from lymph. VLA-5 was identified with clone P1D6 anti- $\alpha_{5}$ $\mathrm{mAb}$, and VLA-4 was identified with anti- $\alpha_{4} \mathrm{mAb}$ clone HP2.1. The data shown are representative of 5 separate experiments. 
adhered to or migrated into the collagen were collected by centrifugation, incubated with phycoerythrin-conjugated anti-CD14 (clone 116) to distinguish the migratory monocytes from other CellTracker Green-labeled MNLs, and then counted by flow cytometry.

Immunoprecipitation and immunoblotting. $10^{7}$ untreated cells or $10^{7} \mathrm{FN} 120$-treated cells were lysed for 45 minutes on ice in $1 \mathrm{~mL} 1 \%$ Triton $\mathrm{X}-100$ buffer. The preparation was centrifuged at $7,500 \mathrm{~g}$ for 30 minutes at $4^{\circ} \mathrm{C}$, and then cleared for 2 hours at $4^{\circ} \mathrm{C}$ with protein A (Sigma Chemical Co.) coupled to rabbit anti-mouse IgG (Organon Teknika Corp.). Proteins reactive with specific antisera were collected by overnight incubation with protein A-agarose beads (Roche Molecular Biochemicals, Indianapolis, Indiana, USA). The beads were subsequently washed with $1 \%$ Triton X-100 buffer and boiled in sample buffer. Eluted proteins were separated by SDSPAGE under reducing conditions $(35,36)$. Proteins in cardiac lymph (diluted 1:20) and cell culture supernatants were fractionated on gradient electrophoresis gels (4-15\% Tris-glycine Ready Gels; Bio-Rad Laboratories Inc., Hercules, California, USA). Nitrocellulose blots of the separated proteins were incubated overnight with antibodies and then exposed to horseradish peroxidase-conjugated second antibody for 1 hour before development with 4-chloro-1-naphthol.

For radioimmunoprecipitation, treated and untreated U937 cells (as above) were surface iodinated with $0.5 \mathrm{mCi}$ ${ }^{125} \mathrm{I}$ by the lactoperoxidase method (37), and then lysed and processed as above. In this case, SDS-PAGE was performed in $11.25 \%$ polyacrylamide gels and autoradiography was performed on Kodak X-OMAT film (Eastman Kodak Co. Scientific Imaging Systems, New Haven, Connecticut, USA). To identify the proteins that may be released from the surface of radioiodinated U937 cells, $10^{7}$ were cultured in serum-free RPMI-1640 for 48 hours. The supernatants were then collected, precleared, immunoprecipitated, fractionated on $10 \%$ polyacrylamide gels, and then autoradiographed.

Statistics. Descriptive statistics included the arithmetic mean and SEM. Comparisons were done using Student's $t$ test or ANOVA with a significance level of $5 \%$. In some Figures, single experiments are used to illustrate results of at least 4 experiments that had the same outcome.
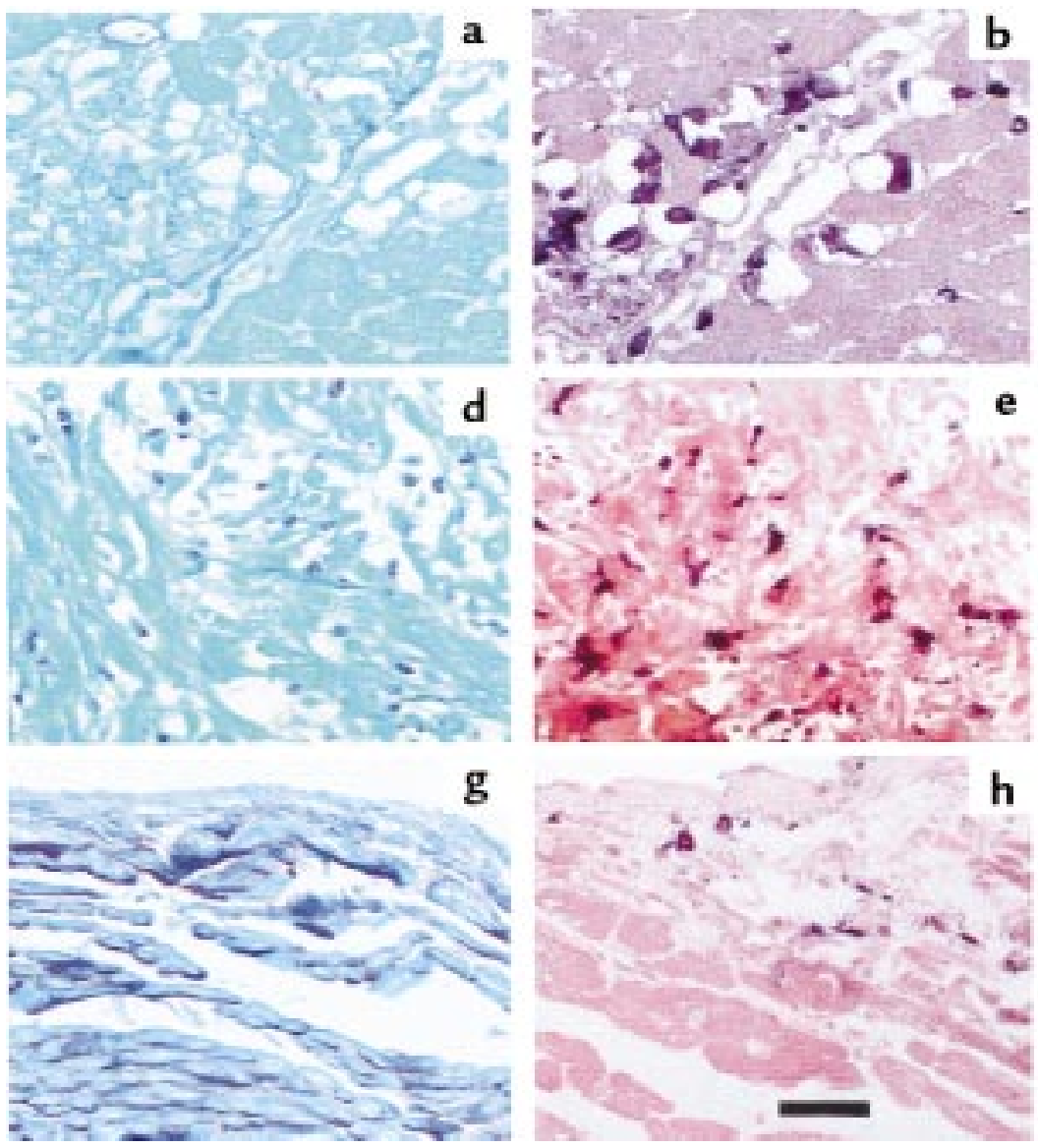

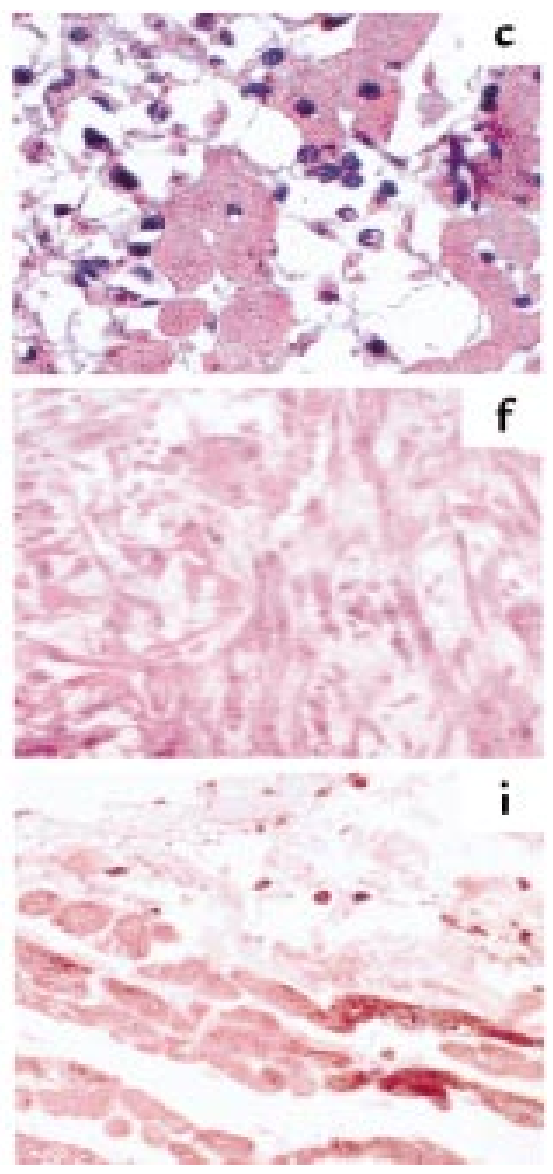

Figure 2

Serial sections of ischemic myocardium collected 3 hours after reperfusion $(\mathbf{a}-\mathbf{c})$ and 5 hours after reperfusion (d-f). Control, nonischemic myocardium, documented by regional myocardial blood flows $(\mathbf{g}-\mathbf{i})$. Sections $\mathbf{a}, \mathbf{d}$, and $\mathbf{g}$ are stained with periodic acid-Schiff to demonstrate the presence of glycogen in normally perfused myocardium $(\mathbf{g})$ and the absence of this substance in infarcted myocardium ( $\mathbf{a}$ and $\mathbf{d}$ ). Sections $\mathbf{b}, \mathbf{e}$, and $\mathbf{h}$ were stained with the AM-3K macrophage-specific antibody, and sections $\mathbf{c}, \mathbf{f}$, and $\mathbf{i}$ were stained for VLA-5. Note that 3 hours after reperfusion, monocytoid cells remain VLA- $5^{+}$for the most part, but after 5 hours, no VLA- $5^{+}$cells can be found in ischemic myocardium rich in $\mathrm{AM}-3 \mathrm{~K}^{+}$macrophages. In the control tissue, the few monocytes/macrophages present stain for VLA-5. Scale bar: $100 \mu \mathrm{m}$. 

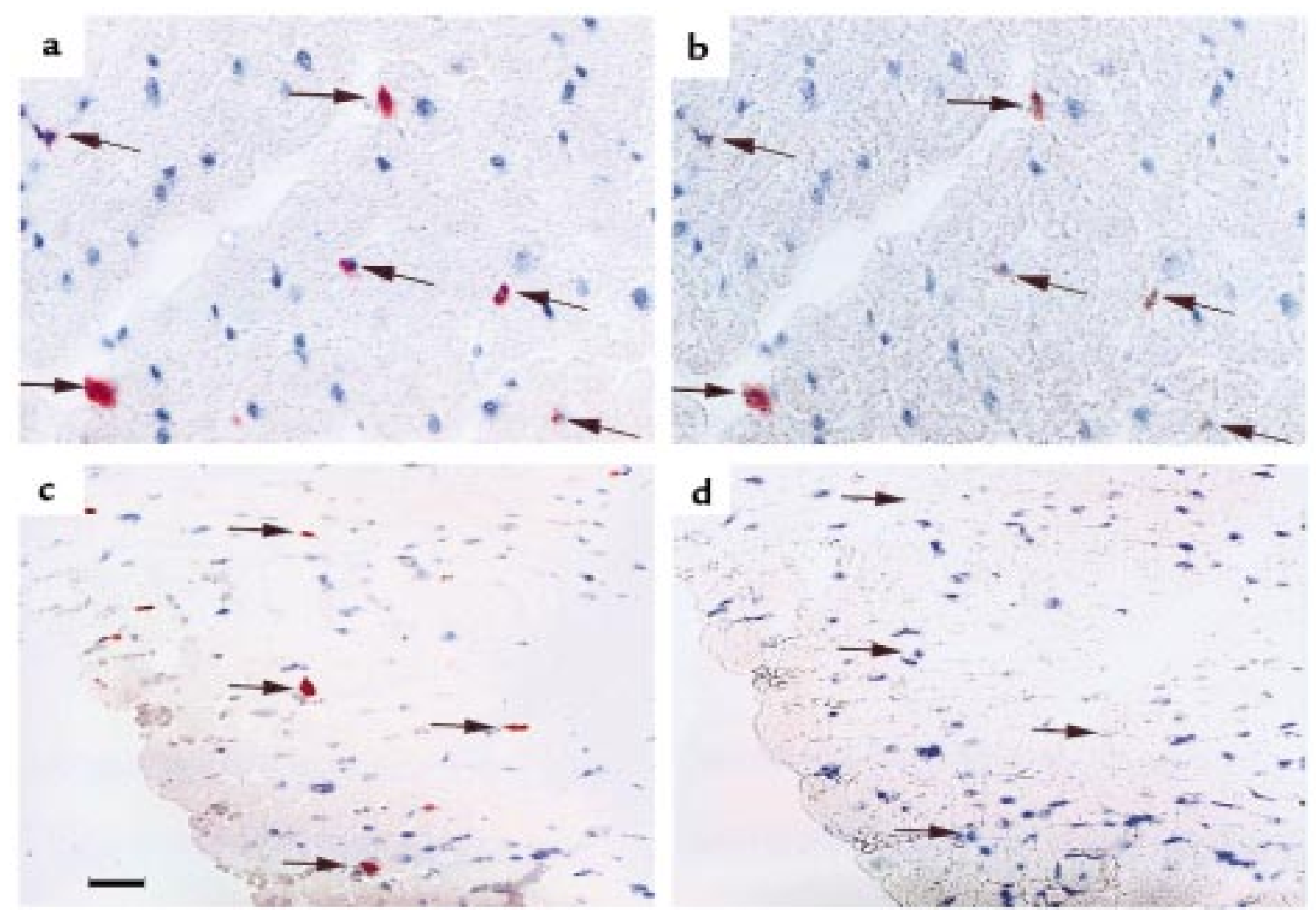

Figure 3

Sections of infarcted myocardium taken 1 hour ( $\mathbf{a}$ and $\mathbf{b})$ and 5 hours ( $\mathbf{c}$ and $\mathbf{d})$ after reperfusion were stained with affinity-purified rabbit antibody against the cytoplasmic domain of $\alpha_{5}$ (AB1928P), and with the monocyte/macrophage-specific AM-3K mAb (see Methods). (a and c) Red monocytes/macrophages (arrows) stained with both antibodies. ( $\mathbf{b}$ and $\mathbf{d}$ ) The same sections after removal of AM-3K and its alcohol-soluble chromogen. Some cells retain orange stain due to attachment of the anti- $\alpha_{5} \mathrm{mAb}$. Three hours after reperfusion, some AM- $3 \mathrm{~K}^{+}$cells are variably stained with anti$\alpha_{5} \mathrm{mAb}$ (compare $\mathbf{a}$ and $\mathbf{b}$ ), whereas 5 hours after reperfusion, none of the AM-3K+ cells react with anti- $\alpha_{5}$ antibodies (compare $\mathbf{c}$ and $\mathbf{d}$ ). All sections were counterstained with hematoxylin. Scale bar: $150 \mu \mathrm{m}$.

\section{Results}

VLA-5 on monocytes released into cardiac lymph after reperfusion. The frequency of VLA $-5^{+}$monocytes in cardiac lymph progressively declined 3 or more hours after reperfusion. Figure 1 shows representative data from a single dog with significant myocardial ischemia. In 4 additional animals with significant myocardial ischemia, the frequency of $\mathrm{CD} 14^{+}$monocytes in cardiac lymph expressing any detectable VLA- 5 decreased to $25 \%, 54 \%, 25 \%$, and $8 \%$ of preocclusion values. Analysis of the combined data from these 5 animals indicated that the decline in VLA $-5^{+}$ monocytes in the lymph after reperfusion was statistically significant $(P=0.01)$. These changes were particularly notable because, in this same model of ischemia-reperfusion injury, we had previously observed that the concentration of monocytes, as a fraction of cardiac lymph leukocytes, progressively increased during this interval. Indeed, within 5 hours after reperfusion, monocyte concentrations in cardiac lymph eventually reach, or even exceed, the concentration of neutrophils (11).

The fraction of VLA- $5^{+}$monocytes in the blood, as well as the numbers of VLA- $4^{+}\left(\alpha_{4} \beta_{1}\right.$ integrin, CD $\left.49 \mathrm{~d} / \mathrm{CD} 29\right)$ monocytes in both cardiac lymph and blood, remained unchanged after reperfusion, as shown in a representa- tive experiment in Figure 1. Therefore, monocyte VLA-5 decreased only on monocytes that ended up in the cardiac lymph; this effect was seen only in animals that experienced significant myocardial ischemia. There were no changes in the frequency of VLA $-5^{+}$or VLA- $4^{+}$monocytes in lymph or blood of animals who, because they had good collateral circulation, failed to experience myocardial ischemia.

VLA-5 expression on canine mononuclear cells infiltrating the heart. Three hours after reperfusion, AM- $3 \mathrm{~K}^{+}$ macrophages were abundant in infarcted myocardium (Figure 2, a-c); serial sectioning suggested that these same areas of infarcted myocardium also contained many VLA $-5^{+}$MNLs. By 5 hours after reperfusion, however, we no longer found leukocytes reactive with anti-VLA-5 in myocardium containing $\mathrm{AM}-3 \mathrm{~K}^{+}$ macrophages (Figure 2, d-f). In control tissues (myocardium that retained normal regional myocardial blood flow during ischemia), areas containing AM- $3 \mathrm{~K}^{+}$ macrophages also contained VLA $-5^{+}$cells (Figure 2, g-i).

Because it was often difficult to find the same monocyte/macrophage in adjacent sections, we could not determine whether specific AM- $3 \mathrm{~K}^{+}$macrophages also expressed VLA-5. Therefore, we treated the same sections 


\section{Figure 4}

FN and FN fragments in cardiac lymph. (a) Cardiac lymph from a dog with ischemia-reperfusion injury. Lanes 1 and 2 (positive controls) show immunoblots of human plasma FN enriched for 40- and 120-kDa FN fragments, respectively. Lanes 3-8 show lymph collected 30-300 minutes after reperfusion. An arrow indicates 120-kDa FN fragments. Brackets indicate smaller FN fragments found in lymph 4-5 hours after reperfusion. (b) Cardiac lymph from an operated dog that, because of good collateral circulation, did not experience cardiac ischemia (lanes 1-6). Almost all FN remains in the native 220-kDa form. Lanes 7 and 8 show human FN enriched for 120- and 40-kDa FN fragments, respectively, to show that FN fragments could have been detected under the conditions of this experiment.

with both antibodies, using different secondary antibodies and distinctive chromogens to identify the respective sites of localization of AM-3K and anti-VLA-5-specific antibodies (Figure 3 ). We found that AM-3K $\mathrm{K}^{+}$cells infiltrating cardiac tissue generally expressed VLA-5 at 3 hours after reperfusion (Figure 3 , $a$ and $b$ ). But AM-3K ${ }^{+}$ macrophages no longer expressed VLA-5 at 3 hours after reperfusion (Figure 3, c and d).

FN fragments in lymph. Because VLA-5 is a receptor for immobilized FN and some of FN's proteolytic fragments (38), we postulated that FN fragments - released during the inflammatory response to ischemic injury - might bind to VLA-5 on monocytes traversing the infarcted myocardium, therefore blocking cell-surface attachment of VLA-5-specific mAb's. After reperfusion, we found that extracellular fluids from ischemic myocardium contained increasing quantities of FN fragments (Figure 4a). At 5 hours, the concentration of FN120 in cardiac lymph was $1.5 \mathrm{mg} / \mathrm{mL}(12.5 \mu \mathrm{M})$. In lymph from dogs (with good collateral circulation) that failed to develop significant regional myocardial ischemia, $\mathrm{FN}$ remained in the intact, high-molecular-weight form (Figure 4b).

Cell-binding FN fragments modulate monocyte VLA-5 expression in vitro. We incubated heparin-anticoagulated peripheral blood at $37^{\circ} \mathrm{C}$ for 90 minutes, either with the 120-kDa VLA-5-binding FN fragment (FN120) or with a 40-kDa gelatin-binding fragment (FN40) that does not interact with VLA-5 (39). FN120 reduced VLA-5 in a dose-dependent manner; FN40 had no such effect (Figure $5 \mathrm{a}$ ). Figure $5 \mathrm{~b}$ shows the change in monocyte VLA-5 fluorescence intensity induced by FN120 treatment.

Table 1

Effect of various agents on VLA-5 expression

\begin{tabular}{lcccc}
\cline { 2 - 2 } & Monocytes & $P$ value & U937 & $P$ value \\
None & $3.7 \pm 0.10$ & & $15.4 \pm 0.20$ & \\
Native FN $(2 \mu \mathrm{M})$ & $4.3 \pm 0.20$ & NS & $16.7 \pm 0.40$ & NS \\
FN120 $(2 \mu \mathrm{M})$ & $2.7 \pm 0.10$ & 0.01 & $13.6 \pm 0.04$ & 0.02 \\
LPS $(10 \mathrm{ng} / \mathrm{mL})$ & $2.8 \pm 0.30$ & 0.04 & $16.1 \pm 0.30$ & NS \\
\hline
\end{tabular}

Monocytes in $100 \mu \mathrm{L}$ of blood, or U937 cells $\left(10^{5}\right)$ in culture medium, were stained without treatment or after a 2 -hour treatment at $37^{\circ} \mathrm{C}$ with indicated agents. After treatment, Fc receptors of U937 cells were blocked by adding $20 \%$ normal human serum for 10 minutes. Experiments were done in triplicate; the mean $\pm \mathrm{SEM}$ is shown for log fluorescence intensity of staining with clone SAM-1 anti-VLA-5. Statistical testing by Student's $t$ test compared values from untreated with values from treated cells in each case. NS, not significant.
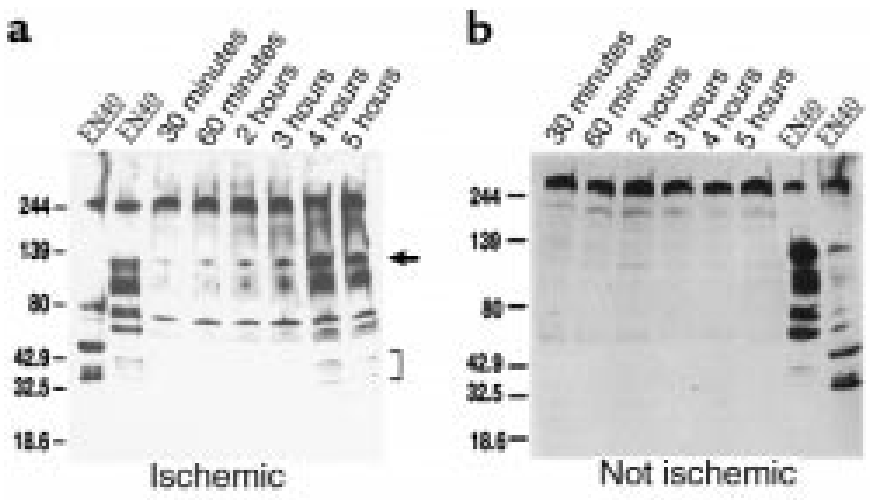

Cardiac lymph

Incubation with FN120, but not with equimolar concentrations of native plasma FN, significantly reduced VLA-5 expression on both blood monocytes and U937 cells (Table 1), indicating that structures revealed by fragmentation of FN were necessary for this effect. Exposure to endotoxin also reduced monocyte VLA-5 (Table 1). But because Limulus assays of the FN120 used in these experiments were negative, it was unlikely that the effects of FN120 resulted from endotoxin contamination. To confirm this, we compared the effects of FN120 and endotoxin on U937 cells, which lack CD14, the LPSbinding protein receptor. Only FN120 decreased U937 VLA-5 expression (Table 1). Incubation with a peptide (GRGDSP) that contains the RGD sequence found in FN120 $(38,40)$ also decreased VLA-5 on both blood monocytes and U937 cells, whereas a control peptide (GRGESP) had no effect (data not shown).

Kinetic analyses showed that monocyte VLA-5 decreased significantly within 5-15 minutes after addition of $2 \mu \mathrm{M}$ FN120 to whole blood at $37^{\circ} \mathrm{C}$ (Figure $5 \mathrm{c}$ ). The decrease in VLA-5 caused by FN120 could be demonstrated with any of 4 anti-VLA- 5 mAb's: clones P1D6, CLB-705, 16, and SAM-1. The fluorescence intensity for VLA-5, as measured with SAM-1, CLB-705, and P1D6, declined 35-40\%, whereas fluorescence intensity measured by the rat $\mathrm{mAb}$, clone 16 , declined by $80 \%$ after addition of FN120.

Quantitative flow cytometric analyses showed that within 2 hours after the addition of $2 \mu \mathrm{M}$ FN120 to whole blood, the number of VLA- 5 binding sites available to the SAM-1 mAb fell from $12,001 \pm 321$ to $9,376 \pm 199$ per monocyte (mean \pm SEM) $(P=0.002$, ANOVA). Under the same conditions, SAM-1 binding sites on U937 cells decreased from $68,247 \pm 300$ to $58,886 \pm 1,573(P=0.004$, ANOVA).

FN fragments produced by infarcted myocardium also decrease monocyte VLA-5 expression. To examine the effects of FN fragments generated in the course of ischemiareperfusion injury on monocyte VLA-5, we incubated $10^{5} \mathrm{U} 937$ cells at $37^{\circ} \mathrm{C}$ for 2 hours with $50 \mu \mathrm{L}$ undiluted postreperfusion cardiac lymph from dogs with myocardial infarctions. This treatment caused monocyte VLA-5 mean fluorescence intensity to fall from 6.3 \pm 0.3 before treatment to $3.2 \pm 0.4$ after treatment $(P=$ 0.003 , Student's $t$ test). When FN and its fragments were removed, the mean fluorescence intensity for VLA-5 in 
lymph-treated samples was $7.1 \pm 0.7$, a value not significantly different from controls. On the other hand, sham-immunoadsorbed lymph that retained a full complement of FN fragments reduced the VLA-5 expression to $3.1 \pm 0.9(P=0.01)$. Similarly, treatment with FNdepleted lymph decreased monocyte VLA-5 expression in whole blood by $13 \%$, whereas sham-immunoadsorbed lymph reduced monocyte VLA- 5 by $34 \%$.

Effect of FN120 on other monocyte cell-surface molecules. Among the $\beta_{1}$ integrins, only VLA-5 was significantly affected by treatment with FN120 (Table 2). Cell-surface molecules other than the $\beta_{1}$ integrins became more abundant. For example, mean fluorescence intensities for CD11b and CD14 rose, respectively, from $11.3 \pm 0.26$ and $6.59 \pm 0.39$ before treatment to $22.0 \pm 1.78$ and 11.8 \pm 0.9 after treatment $(P<0.01$, ANOVA, 3 donors).

Evidence that FN120 induces proteolysis of cell-surface VLA5. We postulated that FN120 blocks VLA-5 antibody binding sites. But when we found no loss of VLA-5 from cells treated at $4^{\circ} \mathrm{C}$ with FN120, this explanation became unlikely (data not shown). To investigate whether metabolism was necessary for the FN120 effect, monocytes were incubated with 2-deoxyglucose and sodium azide, along with FN120, at $37^{\circ} \mathrm{C}$. These agents abolished the effect of FN120 on monocyte VLA-5 expression: mean VLA-5 fluorescence intensity before FN120 treatment was $5.7 \pm 0.1$, and afterwards it was $4.9 \pm 0.2(P<0.01)$. FN120, together with $0.1 \%$ azide and $5 \mathrm{mM} 2$-deoxyglu-

\section{Table 2}

Monocyte surface $\beta_{1}$ integrin chains modulated by FN120

\begin{tabular}{lrrc}
\cline { 2 - 4 } Chain & No treatment & FN120 & $P$ value \\
$\alpha_{4}$ & $1.77 \pm 0.28$ & $1.54 \pm 0.19$ & NS \\
$\alpha_{5}$ & $5.23 \pm 0.18$ & $3.18 \pm 0.13$ & 0.02 \\
$\alpha_{6}$ & $5.20 \pm 0.19$ & $4.11 \pm 0.35$ & NS \\
$\beta_{1}$ & $10.97 \pm 0.49$ & $9.33 \pm 1.26$ & NS
\end{tabular}

Monocytes were stained in whole blood with or without a 2-hour treatment with 2 $\mu \mathrm{M}$ FN120 at $37^{\circ} \mathrm{C}$. Data shown represent mean \pm SEM of the log fluorescent intensity of CD $14^{+}$cells stained with HP2/ 1 for $\alpha_{4}$, with SAM- 1 for $\alpha_{5}$, with $\mathrm{GoH} 3$ for $\alpha_{6}$, and with 33B6 for $\beta_{1}$. Data were obtained from 3 different donors. $P$ values measured by Student's $t$ test. NS, not significant.

cose, produced a mean fluorescence intensity of $5.6 \pm 0.4$, a value not different from untreated controls.

To investigate the possibility that FN120 initiates hydrolysis of VLA-5, we added PMSF (which blocks serine proteases), $\mathrm{CdCl}_{2}$ and bestatin (which block leucine aminopeptidases), 1,10-phenanthroline (which blocks arylamidases and aminopeptidases), and EGTA (which blocks metalloproteases) to whole blood before adding FN120 (Table 3). Among these, only PMSF blocked the FN120 effect. Subsequently, we found that aprotinin, another serine protease inhibitor, also prevents FN120induced loss of VLA-5 (data not shown).

FN120 treatment causes fragmentation of monocyte VLA-5 molecules. We treated $10^{7} \mathrm{U} 937$ cells with $5 \mathrm{nmol}$ of FN120 for 5 hours, and then we surface labeled these

\section{Figure 5}

Effect of 40-kDa (FN40) and 120-kDa (FN120) fragments of FN on VLA-5 expressed by CD14+ monocytes in human blood. Graphs in a and $\mathbf{c}$ show the mean \pm SEM for data obtained from 3 different donors. (a) Dose response. Data show mean fluorescence intensity for staining with the anti- $\alpha_{5} \mathrm{mAb}$ clone SAM-1. Open squares represent FN40 treatment; filled squares represent FN120 treatment. Asterisks indicate data that differ significantly from untreated sample values $(P$ $<0.05$, ANOVA). The mean fluorescence intensity for an isotypematched control mouse immunoglobulin ranged from 0.21 to 0.28 for all donors and treatments. (b) Histogram compares log immunofluorescence intensity for monocytes treated (FN120) or not treated (no $\mathrm{Rx}$ ) with $2 \mu \mathrm{M}$ FN120 for 2 hours before staining with mAb clone SAM-1. The solid line represents isotype-matched control mouse immunoglobulin. (c) Kinetic analysis of response to $2 \mu \mathrm{M}$ FN120. Filled triangle represents the mean fluorescence intensity of clone SAM- 1 anti- $\alpha_{5}$ on CD14 ${ }^{+}$human monocytes in whole blood. Aliquots of this blood sample were left untreated (open squares, no Rx) or treated with FN120 (filled squares, FN120). Asterisks indicate times at which results differ significantly $(P<0.05$, ANOVA) from the time 0 value. Note that VLA-5 expression was significantly reduced within 5 minutes after addition of FN120. The mean fluorescence intensity for an isotype-matched control mouse immunoglobulin ranged from 0.23 to 0.29 for all donors and treatments. a

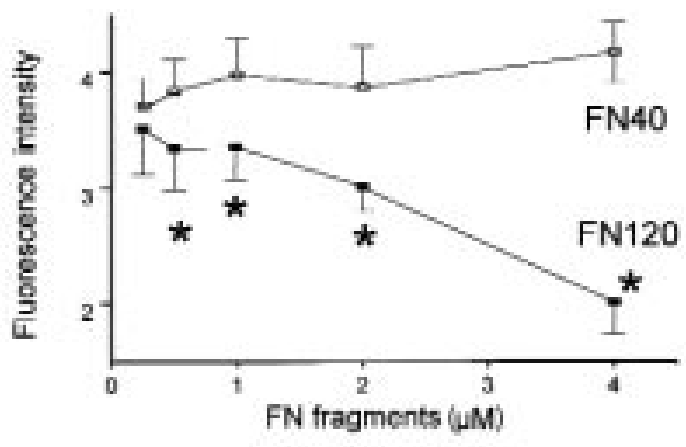

b

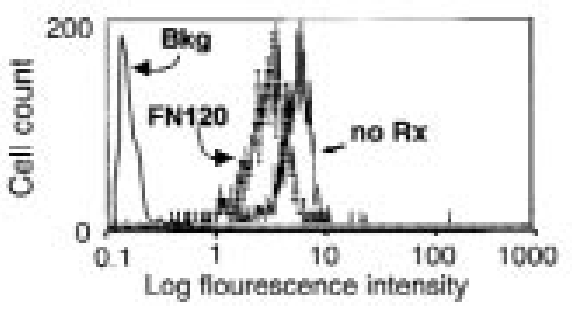

C

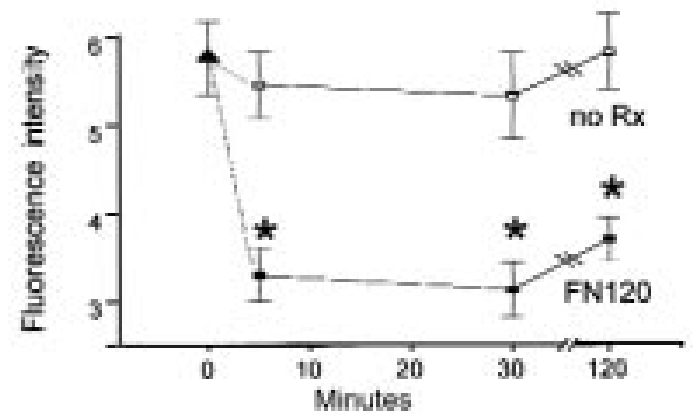


and an equal number of untreated U937 cells with ${ }^{125} \mathrm{I}$. Unbound ${ }^{125}$ I was removed and the cells were lysed. Proteins reactive with antibodies to the cytoplasmic domain of the $\alpha_{5}$ chain were immunoprecipitated and analyzed by SDS-PAGE (Figure 6a). Fragments of $\alpha_{5}$ were found only in lysates of cells incubated with FN120.

We also found that ${ }^{125}$ I-labeled U937 cells, treated with FN120 as described above, shed released VLA-5 when placed in serum-free media for 48 hours. Supernatants of these cells contained not only full-length, $150-\mathrm{kDa} \alpha_{5}$, but also $\alpha_{5}$ fragments that migrated under reducing conditions at $\sim 97 \mathrm{kDa}, \sim 70 \mathrm{kDa}$, and $45 \mathrm{kDa}$ (Figure 6a, lane 3).

To evaluate whether this fragmentation of $\alpha_{5}$ was related to the lactoperoxidase treatment used in the ${ }^{125}$ I surface labeling of the U937 cells, we also analyzed detergent lysates of unlabeled U937 cells, treated or not treated with FN120. Figure $6 \mathrm{~b}$ shows immunoblots of U937 lysates that were immunoprecipitated with rabbit anti- $\beta_{1}$ (CD29), fractionated by SDS-PAGE, and then probed with anti- $\alpha_{5}$ antibodies. Whereas the $150-\mathrm{kDa} \alpha_{5}$ a

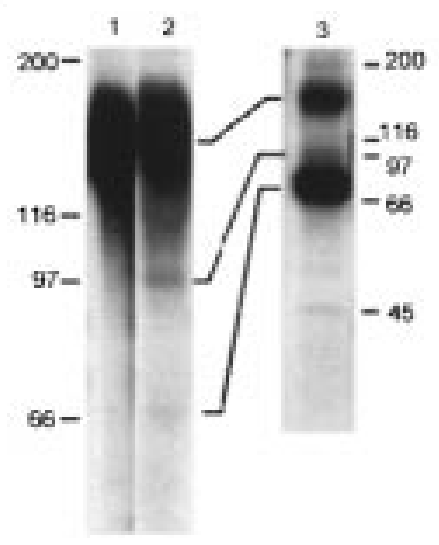

d

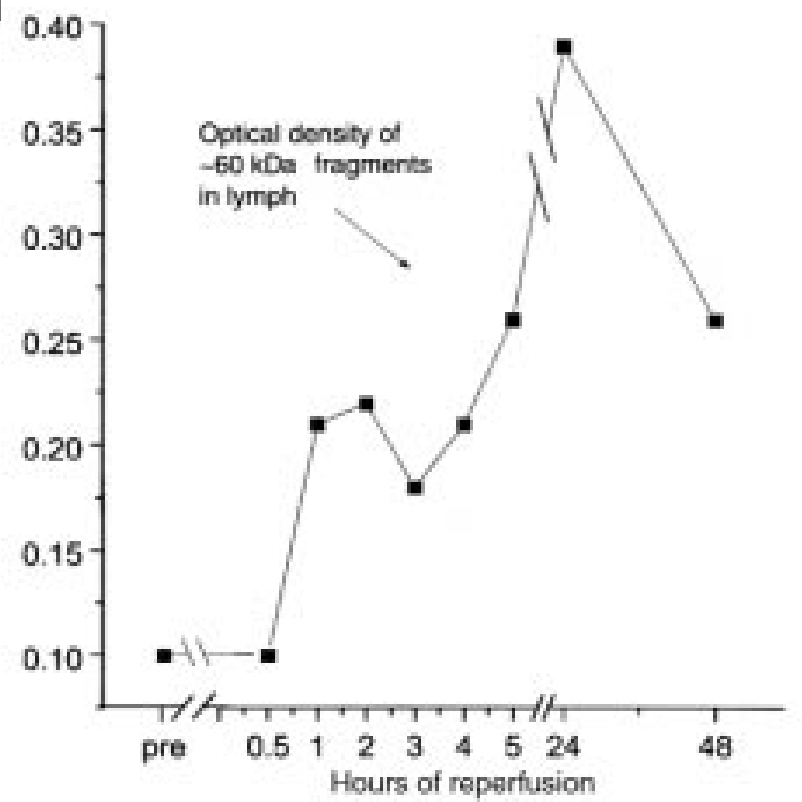

C
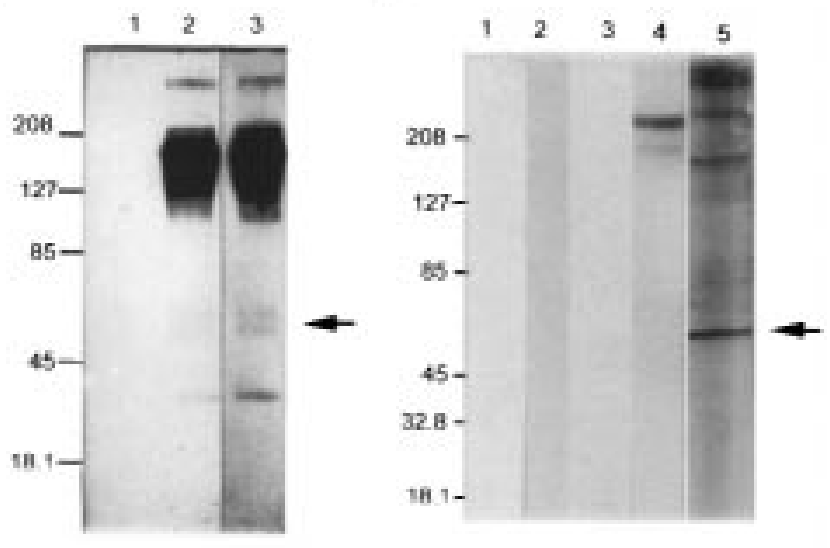

e

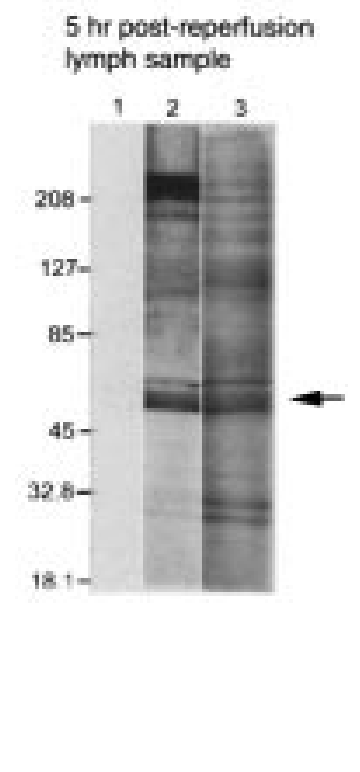

Figure 6

Fragmentation of cell-surface VLA-5 after exposure to FN120. (a) Lysates of U937 cells, surface labeled with ${ }^{125}$, were immunoprecipitated by affinity-purified antibodies to $\alpha_{5}$ and then fractionated by SDS-PAGE before radioautography. Lane 1, untreated cells; lane 2, FN120-treated cells; and lane 3 , anti- $\alpha_{5}$ immunoprecipitates of culture supernatants of radiolabeled cells, previously exposed to FN120, demonstrating the release of $\alpha_{5}$ fragments. (b) Lysates of U937 cells were immunoprecipitated with rabbit antibody to $\beta_{1}$, fractionated, blotted to nitrocellulose, and then probed with affinity-purified rabbit antibodies to the cytoplasmic domain of $\alpha_{5}$ (lanes 2 and 3). Lane 1, lysates incubated only with the secondary antibody; lane 2 , proteins from untreated cells; lane 3, proteins from FN120-treated cells in lanes 1 and 3 . An arrow indicates that the 60-kDa fragment was more prominent after FN120 treatment. (c) U937 cells cultured with or without FN120. Lanes 1 and 3, supernatants from untreated cells; lanes 2, 4, and 5 , supernatants from FN120-treated cells. Immunoblots probed with second antibody only (lanes 1 and 2 ), with anti- $\beta_{1}$ antibodies (lanes 3 and 4 ), or with antibodies to the cytoplasmic domain of $\alpha_{5}$ (lane 5). Note the $60-\mathrm{kDa}$ fragment identified with anti- $\alpha_{5}$ antibodies. (d) Serial densitometric measurements of a $60-\mathrm{kDa} \alpha_{5}$ fragment in immunoblots of cardiac lymph collected at intervals before occlusion and for 48 hours after reperfusion in a dog with significant myocardial ischemia. (e) Immunoblot of cardiac lymph collected 5 hours after reperfusion of ischemic myocardium. Lane 1 was developed with only second antibody; lane 2 with anti- $\beta_{1}$; and lane 3 with antibodies to the cytoplasmic domain of $\alpha_{5}$. The arrow beside lane 3 indicates a prominent $60-\mathrm{kDa}$ fragment detected by anti- $\alpha_{5}$ antibodies. 
molecule was dominant, $\sim 60-\mathrm{kDa}$ and $\sim 40-\mathrm{kDa} \alpha_{5}$ fragments were also found in these immunoprecipitates. Fragments of this size were only faintly evident in immunoprecipitates of cells cultured in the absence of FN120 (Figure 6b, compare lanes 2 and 3).

Differences in the gels or conditions used to fractionate the lysates of the ${ }^{125}$ I-tagged and the unlabeled U937 cells may be responsible for some of the differences in the estimated molecular weights of the VLA-5 fragments we identified. Indeed, with shorter exposure times, autoradiographs of the $\sim 70-\mathrm{kDa},{ }^{125}$ I-labeled $\alpha_{5}$ fragment (Figure 6a, lane 2 ) appeared as a doublet similar to the $\sim 60-\mathrm{kDa}$ fragment seen in Figure 6b, lane 3.

In supernatants of unlabeled U937 cells (Figure 6c, lane 4$)$, proteins reactive with anti- $\beta_{1}$ antibodies were evident only after treatment with FN120. At more than 200 $\mathrm{kDa}$, these molecules were not fragments. Rather, their size and resistance to reducing agents suggested that they may be the spontaneously forming $\beta_{1}$ homodimers found by others in studies of integrins extracted from smooth muscle cells (41). Supernatants of FN120-treated U937 cells, on the other hand, contained many $\alpha_{5}$ fragments (Figure 6c, lane 5). Prominent among these was an $\sim 60-\mathrm{kDa}$ species (Figure $6 \mathrm{c}$, arrow) similar in molecular weight to the fragment, reactive with anti- $\alpha_{5}$ antibodies, found in lysates of FN120-treated U937 cells (compare Figure 6b, lane 3, and 6c, lane 5).

We also found fragments reactive with anti- $\alpha_{5}$ in cardiac extracellular fluids after myocardial infarctions. Figure 6 e shows immunoblots of a cardiac lymph sample collected 5 hours after reperfusion. Proteins reactive with anti- $\beta_{1}$ (Figure $6 e$, lane 2 ) and anti- $\alpha_{5}$ (Figure 6e, lane 3 ) were identified. As in the immunoblots of FN120-treated U937 cell culture supernatants, anti- $\beta_{1}$ antibodies recognized a protein larger than $200 \mathrm{kDa}$ in these cardiac lymph samples (Figure 6e, lane 2 ). In addition, there were numerous fragments. The antibodies to $\alpha_{5}$ also reacted with many proteins in the lymph (Figure 6e, lane 3 ), most notably an $\sim 60-\mathrm{kDa}$ species (arrow in Figure 6e) similar in molecular weight to the $\sim 60-\mathrm{kDa}$ protein(s) found in lysates (Figure 6, a and b) and culture supernatants (Figure 6c) of FN120-treated U937 cells.

Although both anti- $\alpha_{5}$ and anti- $\beta_{1}$ antibodies reacted with a cluster of proteins $\sim 60 \mathrm{kDa}$ in size in these immunoblots, it cannot be inferred that these are necessarily the same protein(s). It is more likely that they are
Table 3

Effect of protease inhibitors on modulation of VLA-5 by FN120

$\begin{array}{lccc} & \text { No treatment } & \text { FN120 } & P \text { value } \\ \text { Nonent } & 4.7 \pm 0.5 & 2.3 \pm 0.3 & <0.03 \\ \text { PMSF } & 5.4 \pm 0.4 & 5.8 \pm 0.7 & \mathrm{NS} \\ \mathrm{CdCl}_{2} & 4.7 \pm 0.5 & 2.2 \pm 0.3 & <0.03 \\ \text { Bestatin } & 4.9 \pm 0.3 & 2.4 \pm 0.5 & <0.03 \\ \text { Phenanthroline } & 4.9 \pm 0.6 & 3.1 \pm 0.6 & <0.03 \\ \text { EGTA } & 5.1 \pm 0.3 & 2.8 \pm 0.6 & <0.03\end{array}$

Monocytes in blood were exposed to $2 \mu \mathrm{M}$ FN120 or left untreated for 2 hours at $37^{\circ} \mathrm{C}$. Inhibitors were added at the initiation of treatment: $0.2 \mathrm{mM}$ PMSF, 2 $\mathrm{mM} \mathrm{CdCl}_{2}, 40 \mu \mathrm{M}$ bestatin, $10 \mu \mathrm{M}$ 1,10-phenanthroline, and $0.1 \mathrm{mM}$ EGTA. Values represent mean \pm SEM of the log fluorescent intensity of CD $14^{+}$cells stained with SAM- 1 for $\alpha_{5}$. Data were obtained from 3 different donors. $P$ values measured by Student's $t$ test. NS, not significant.

distinct $\alpha_{5}$ and $\beta_{1}$ fragments with similar electrophoretic mobilities. Alternatively, these may be adducts of $\alpha_{5}$ and $\beta_{1}$ fragments. Macrophages reportedly display cellsurface transamidases that, upon activation by FN fragments, cause fibrin and cell membrane components to couple covalently (42). Conceivably, such enzymes could also couple $\alpha_{5}$ and $\beta_{1}$ fragments.

Densitometric measurement of the $\sim 60-\mathrm{kDa} \alpha_{5}$ fragment(s) in cardiac lymph samples (Figure 6d) indicates that proteolysis of VLA-5 molecules on leukocytes migrating into ischemic heart tissue began during the first hour after reperfusion. This process continued throughout the first 24 hours after reperfusion, only decreasing 48 hours after reperfusion.

How does the loss of VLA-5 affect monocyte migration on tissue matrix? Using the matrix interaction assay described in Methods, we counted the monocytes that spontaneously migrated into, and remained within, polymerized collagen pads 4 hours after application of MNLs to the surface of the pad. Significantly more monocytes accumulated in collagen that incorporated $20 \mu \mathrm{g} / \mathrm{mL}$ native FN compared with collagen alone (Table 4, columns 1 and 2). Pretreatment with $2 \mu \mathrm{M}$ FN120 reduced the numbers of monocytes that lodged in the FN-collagen pads (Table 4, compare columns 2 and 4; $P<0.04,4$ experiments). On the other hand, in 3 of 4 experiments, pretreatment with this same concentration of FN120 had no significant effect on the numbers of monocytes that accumulated in collagen by itself (Table 4, compare columns 1 and 3), nor did FN120

Table 4

Monocyte accumulation in collagen pads after modulation of VLA-5 with FN120

\begin{tabular}{|c|c|c|c|c|c|c|c|}
\hline \multirow[b]{3}{*}{ Columns } & \multicolumn{4}{|c|}{ Treatment } & & & \\
\hline & \multicolumn{2}{|c|}{ None } & \multicolumn{2}{|c|}{ FN120 } & \multicolumn{3}{|c|}{$P$ values (columns) } \\
\hline & 1 & 2 & 3 & 4 & & & \\
\hline Donor & Collagen & Collagen + FN & Collagen & Collagen + FN & 1 vs. 2 & 1 vs. 3 & 2 vs. 4 \\
\hline 1 & $2,043 \pm 157$ & $4,185 \pm 218$ & $2,223 \pm 311$ & $707 \pm 54$ & 0.02 & NS & 0.002 \\
\hline 2 & $2,064 \pm 448$ & $3,402 \pm 307$ & $850 \pm 223$ & $1,725 \pm 222$ & 0.03 & NS & 0.04 \\
\hline 3 & $778 \pm 68$ & $2,346 \pm 191$ & $424 \pm 87$ & $591 \pm 31$ & 0.006 & 0.02 & 0.01 \\
\hline 4 & $1,036 \pm 155$ & $3,741 \pm 552$ & $852 \pm 40$ & $1,012 \pm 196$ & 0.01 & NS & 0.03 \\
\hline
\end{tabular}

MNLs (donors 1-3) or elutriated monocytes (donor 4) were untreated or treated with $2 \mu \mathrm{M} \mathrm{FN} 120$ for 90 minutes at $37^{\circ} \mathrm{C}$. Cells were added $\left(8 \times 10^{5} \mathrm{MNLs}\right.$ or $10^{5}$ elutriated monocytes) to pads made with polymerized collagen alone or collagen plus $20 \mu \mathrm{g} / \mathrm{mL}$ of FN (Collagen $+\mathrm{FN}$ ). Cells were allowed to migrate for 4 hours at $37^{\circ} \mathrm{C}$ in humidified air containing $5 \% \mathrm{CO}_{2}$, after which nonadherent cells were removed and migratory cells were freed from the matrix with collagenase. Monocytes were identified by staining with anti-CD14 and were counted by flow cytometry. Data represent the number of CD14 monocytes per pad \pm SEM of triplicate wells. $P$ values were derived by ANOVA. 
treatment influence the numbers of monocytes that migrated into collagen containing $20 \mu \mathrm{g} / \mathrm{mL}$ laminin. After a 4-hour incubation, we found 5,826 \pm 538 untreated vs. 5,525 \pm 639 FN120-treated monocytes from 1 donor, and 1,298 \pm 161 untreated vs. 1,266 \pm 139 FN120-treated monocytes from a second donor in the collagen-laminin matrix.

The effect of FN120 on monocyte migration in response to the chemotactic activity of MCP-1 was subtly different. In 1 case, FN120 treatment decreased the numbers of monocytes migrating through collagen alone from $2,997 \pm 418$ to $1,205 \pm 198(P=0.017)$; the numbers of monocytes from this donor migrating through a collagen -FN matrix likewise decreased from $3,818 \pm 767$ to $1,725 \pm 222$ after FN120 treatment $(P=$ $0.04)$. With MNLs from a second donor, we found that FN120 treatment reduced the numbers of monocytes accumulating in collagen alone in response to MCP-1 from $3,186 \pm 486$ to $656 \pm 144(P=0.007)$. With cells from this same donor, FN120 treatment decreased monocyte migration through a collagen-FN matrix from $2,520 \pm 797$ to $1,312 \pm 156(P=0.004)$.

\section{Discussion}

FN is a prominent component of cardiac tissue matrix (43). Previous studies had shown that ischemic injury causes focal release of proteases that break down FN, producing fragments with potentially important signaling properties $(21,22,44,45)$. For example, Clark et al. (23) showed that nanomolar concentrations of certain cellbinding fragments of FN are chemotactic for monocytes. Thus, in ischemic myocardium, we reasoned that monocytes migrate toward sites where proteases are actively degrading extracellular matrix proteins, and thereby producing FN fragments. On the other hand, micromolar concentrations of these same cell-binding FN fragments, perhaps sufficient to saturate all cell-surface receptors, are reportedly not chemotactic (23). Therefore, our hypothesis was that high concentrations of FN fragments, as would be found in the epicenter of a myocardial infarction, interfere with monocyte migration.

Data presented here support the idea that cell-binding FN fragments, acting upon the monocyte FN receptor VLA-5, help to regulate monocyte interactions with tissue matrix. However, they act not by saturating or desensitizing VLA-5, but by inducing proteolysis of the $\alpha_{5}$ chain of this heterodimeric molecule. Two lines of evidence support this conclusion. First, incubation with purified FN120 or postreperfusion cardiac lymph that is rich in FN fragments reduced the quantity of VLA-5 expressed by monocytoid cells and caused them to release $\alpha_{5}$ fragments extracellularly. Second, treating the cells with serine protease inhibitors reduced the ability of FN120 to stimulate monocyte VLA-5 shedding. Because incubation with FN120 induced proteolysis of $\alpha_{5}$ even in the absence of plasma, and because the effect of FN120 was blocked by incubating the cells with metabolic inhibitors, it is likely that the protease responsible is an inducible product of the monocyte. Thus, VLA-5 may be among the cell-surface molecules whose expression and physiological function is modulated by endogenous proteases (46-48).

Experiments that measured the numbers of monocytes migrating into collagen containing native FN suggested that adhesive interactions between VLA- 5 and FN significantly enhance both spontaneous and MCP-1-driven monocyte migration into a model tissue matrix. Treatment with FN120 reduced - but did not abolish migration into collagen spiked with FN; it also reduced MCP-1-stimulated monocyte migration into polymerized collagen that lacked any additives. Because MCP-1 also stimulates $\beta_{2}$ and $\beta_{1}$ integrin-dependent monocyte adherence to collagen and laminin (49), it is possible that costimulation with MCP-1 and FN120 influences the expression and/or function of other ligands that are used by monocytes when interacting with FN-deficient extracellular matrices. We found that FN120 did not affect spontaneous monocyte migration into polymerized collagen or collagen that contained $20 \mu \mathrm{g} / \mathrm{mL}$ of laminin. Using a very different matrix interaction assay, Pacifici et al. reported that FN120 stimulates $\alpha_{2} \beta_{1}$-dependent monocyte adherence to denatured collagen (50).

It is possible that interactions with matrix proteins involving neither VLA5 nor FN, including, perhaps, adhesive interactions that depend upon CD49f (VLA-6) $(51,52)$ or CD36 $(53)$, enable monocytes to migrate into infarcted myocardium that has been depleted of native FN. Indeed, proteolysis of matrix FN may promote the survival of monocytes that have entered infarcted tissue. Sugahara et al. have reported that VLA-5-mediated adhesion of monocytes to native FN induces apoptosis (54). A microenvironment that is relatively deficient in FN may therefore allow monocytes to differentiate into the tissue macrophages that are known to orchestrate repair of the damaged myocardium $(13,55,56)$.

Previously, we observed that reperfusion of ischemic injury significantly increased the flow of monocytes through the heart into the cardiac lymph, where, by 5 hours after reperfusion, they are as abundant as neutrophils (11). In this report, we show that postreperfusion cardiac lymph contains progressively increasing amounts of FN fragments; most notably, they are fragments that induce proteolysis of monocyte cell-surface VLA-5. By the 3 hours after reperfusion, relatively few of the monocytes in the cardiac lymph express VLA-5. A cause-and-effect relationship between the appearance of FN fragments in lymph and the loss of monocyte VLA-5 in vivo was suggested by experiments showing that removal of FN significantly reduced the capacity of the postreperfusion lymph to induce $\alpha_{5}$ shedding in vitro. Encounters with FN fragments responsible for the loss of VLA-5 from migrating monocytes may happen in the reperfused myocardium. But our data do not exclude the possibility that shedding of VLA-5 by monocytes that migrate into the lymph occurs only after their encounter with lymph fluids that contain high concentrations of cell-binding FN fragments. It is not clear whether loss of cell-surface VLA-5 influences monocyte migration from the cardiac interstitial space into the cardiac lymphatics.

To fully explain the movement of these cells from the heart into the cardiac lymphatics, it will be necessary to identify not only the mechanisms that enable monocytes to migrate through extracellular matrix, but also those that enable these cells to cross the lymphatic endothelium. Recent studies report that cell-surface display of $\mathrm{p}$ - 
glycoprotein (MDR-1), a protein previously recognized for its ability to mediate transport of molecules from the intracellular compartments of malignant cells (57), is required for cutaneous $T$ lymphocytes and dendritic cells to migrate into dermal lymphatics. The expression of similar molecules may regulate monocyte transendothelial trafficking in myocardium damaged by ischemiareperfusion injury.

\section{Acknowledgments}

This research was supported by the Houston Veterans Affairs Medical Center; a grant-in-aid from the American Heart Association, Texas Affiliate; and National Institutes of Health-Department of Health and Human Services grants HL-42550, NS-32583, and CA62596. We thank Merry Lindsey for help with dog lymph collection and storage.

1. Cowan, M.J., Reichenbach, D., Turner, P., and Thostenson, C. 1991. Cellular response of the evolving myocardial infarction after therapeutic coronary artery reperfusion. Hum. Pathol. 22:154-163.

2. Rossen, R.D., and Mann, D.L. 1996. Myocardial inflammation. In Immunology: principles and practice. R.R. Rich, editor. C.V. Mosby and Co. St. Louis, MO. 1463-1481

3. Boyle, M.P., and Weisman, H.F. 1993. Limitation of infarct expansion and ventricular remodeling by late reperfusion. Circulation. 88:2872-2883.

4. Morita, M., Kawashima, S., Ueno, M., Kubota, A., and Iwasaki, T. 1993 Effects of late reperfusion on infarct expansion and infarct healing in conscious rats. Am. J. Pathol. 143:419-430.

5. Buckley, B.H., and Roberts, W.C. 1974. Steroid therapy during acute myocardial infarction: a cause of delayed healing and ventricular aneurysm. Am. J. Med. 56:244-250.

6. Roberts, R., DeMello, V., and Sobel, B.E. 1976. Deleterious effects of methyl-prednisolone in patients with myocardial infarction. Circulation. 53:(Suppl. 1):1204-1206.

7. Hammerman, H., Kloner, R.A., Hale, S., Schoen, F.J., and Braunwald, E. 1983. Dose-dependent effects of short-term methylprednisolone on myocardial infarct extent, scar formation and ventricular function. Cir culation. 68:446-452.

8. Hammerman, H., et al. 1983. Indomethacin-induced scar thinning after experimental myocardial infarction. Circulation. 67:1290-1295.

9. Sommers, H.M., and Jennings, R.B. 1964. Experimental acute myocardial infarction. Histologic and histochemical studies of early myocardial infarcts induced by temporary or permanent occlusion of a coronary artery. Lab. Invest. 13:1491-1503.

10. Dreyer, W.J., et al. 1991. Neutrophil accumulation in ischemic canine myocardium. Circulation. 84:400-411.

11. Birdsall, H.H., et al. 1997. Complement C5a, TGF $\beta 1$ and MCP-1, in sequence, induce migration of monocytes into ischemic myocardium within the first 1 to 5 hours following reperfusion. Circulation. 95:684-692.

12. Weihrauch, D., Zimmermann, R., Arras, M., and Schaper, J. 1994. Expression of extracellular matrix proteins and the role of fibroblasts and macrophages in repair processes in ischemic porcine myocardium. Cell. Mol. Biol. Res. 40:105-116.

13. Weihrauch, D., Arras, M., Zimmermann, R., and Schaper, J. 1995. Importance of monocytes/macrophages and fibroblasts for healing of micronecroses in porcine myocardium. Mol. Cell. Biochem. 147:13-19.

14. Arras, M., et al. 1998. Tumor necrosis factor-alpha is expressed by monocytes/macrophages following cardiac microembolization and is antagonized by cyclosporin. Basic Res. Cardiol. 93:97-107.

15. Reuterdahl, C., Sundberg, C., Rubin, K., Funa, K., and Gerdin, B. 1993. Tissue localization of beta receptors for platelet derived growth factor and platelet derived growth factor B chain during wound repair in humans. J. Clin. Invest. 91:2065-2075.

16. Pierce, G.F., Mustoe, T.A., Altrock, B.W., Deuel, T.F., and Thomason, A. 1991. Role of platelet-derived growth factor in wound healing. J. Cell. Biochem. 45:319-326.

17. Pierce, G.F., et al. 1989. Platelet-derived growth factor and transforming growth factor-beta enhance tissue repair activities by unique mechanisms. J. Cell Biol. 109:429-440.

18. Pierce, G.F., Brown, D., and Mustoe, T.A. 1991. Quantitative analysis of inflammatory cell influx, procollagen type I synthesis, and collagen cross-linking in incisional wounds: influence of PDGF-BB and TGF-beta 1 therapy. J. Lab. Clin. Med. 117:373-382.
19. Cromack, D.T., Porras, R.B., and Mustoe, T.A. 1990. Current concepts in wound healing: growth factor and macrophage interaction. J. Trauma. 30(Suppl.): 129-133.

20. Brown, E.J., and Goodwin, J.L. 1988. Fibronectin receptors of phagocytes. J. Exp. Med. 167:777-793.

21. Doherty, D.E., Henson, P.M., and Clark, R.A. 1990. Fibronectin fragments containing the RGDS cell-binding domain mediate monocyte migration in the rabbit lung. J. Clin. Invest. 86:1065-1075.

22. Clemmensen, I., and Anderson, R.B. 1982. Different molecular forms of fibronectin in rheumatoid synovial fluid. Arthritis Rheum. 25:25-31.

23. Clark, R.A., Wikner, N.E., Doherty, D.E., and Norris, D.A. 1988. Cryptic chemotactic activity of fibronectin for human monocytes resides in the 120-kDa fibroblastic cell-binding fragment. J. Biol. Chem. 263:12115-12123

24. Yonemasu, K., Nakanishi, A., Sasaki, T., and Kashiba, S. 1983. Stimulation of locomotion of peripheral blood monocytes by human plasma fibronectin. Microbiol. Immunol. 27:283-290.

25. Yamada, K.M., and Kennedy, D.W. 1984. Dualistic nature of adhesive protein function: fibronectin and its biologically active peptide fragments can autoinhibit fibronectin function. J. Biol. Chem. 99:29-36.

26. Michael, L.H., et al. 1985. Creatine kinase and phosphorylase in cardiac lymph: coronary occlusion and reperfusion. Am. J. Physiol. 248:350-359.

27. Rossen, R.D., et al. 1988. Mechanism of complement activation after coronary artery occlusion: evidence that myocardial ischemia in dogs causes release of constituents of myocardial subcellular origin that complex with human C1q in vivo. Circ. Res. 62:572-584.

28. Dreyer, W.J., et al. 1989. Canine neutrophil activation by cardiac lymph obtained during reperfusion of ischemic myocardium. Circ. Res. 65:1751-1762.

29.Zeng, L., Takeya, M., Ling, X., Nagasaki, A., and Takahashi, K. 1996. Interspecies reactivities of anti-human macrophage monoclonal antibodies to various animal species. J. Histochem. Cytochem. 44:845-853.

30. Zeng, L., Takeya, M., and Takahashi, K. 1996. AM-3K, a novel monoclonal antibody specific for tissue macrophages and its application to pathological investigation. J. Pathol. 178:207-214.

31. Youker, K.A., et al. 1994. Molecular evidence for induction of intercellular adhesion molecule- 1 in the viable border zone associated with ischemia-reperfusion injury of the dog heart. Circulation. 89:2736-2746.

32. Stouffer, G.A., et al. 1998. Beta3 integrins are upregulated after vascular injury and modulate thrombospondin- and thrombin-induced proliferation of cultured smooth muscle cells. Circulation. 97:907-915.

33. Forsyth, K.D., and Levinsky, R.J. 1990. Preparative procedures of cooling and re-warming increase leukocyte integrin expression and function on neutrophils. J. Immunol. Methods. 128:159-163.

34. Birdsall, H.H., et al. 1997. Transendothelial migration of lymphocytes from HIV-1 infected donors. A mechanism for extravascular dissemination of HIV-1. J. Immunol. 158:5968-5977.

35. Baughn, R.E. 1986. Antibody-independent interactions of fibronectin, $\mathrm{C} 1 \mathrm{q}$, and human neutrophils with Treponema pallidum. Infect. Immun. 54:766-773.

36. Baughn, R.E., Demecs, M., Taber, L.H., and Musher, D.M. 1996. Epitope mapping of B-cell determinants on the 15-kilodalton lipoprotein of Treponema pallidum (Tpp15) with synthetic peptides. Infect. Immun. 64:2457-2466.

37. Keski-Oja, J., Mosher, D.F., and Vaheri, A. 1977. Dimeric character of fibronectin, a major cell surface-associated glycoprotein. Biochem. Biophys. Res. Commun. 74:699-706.

38. Wright, S.D., and Meyer, C.B. 1985. Fibronectin receptor of human macrophages recognizes the sequence arg-gly-asp-ser. J. Exp. Med. 162:762-767.

39. Ruoslahti, E., and Hayman, E.G. 1979. Two active sites with different characteristics in fibronectin. FEBS Lett. 97:221-224.

40. Pierschbacher, M.D., Hayman, E.G., and Ruoslahti, E. 1982. Synthetic peptide with cell attachment activity of fibronectin. Proc. Natl. Acad. Sci. USA. 80:1224-1227.

41. Belkin, V.M., Kozlova, N.I., Bychkova, V.V., and Shekhonin, B.V. 1996. Beta 1 integrin subunit dimerization via disulfide bonds. Biochem. Mol. Biol. Int. 40:53-60.

42. Hormann, H., Richter, H., and Jelinic, V. 1987. The role of fibronectin fragments and cell-attached transamidase on the binding of soluble fibrin to macrophages. Thromb. Res. 46:39-50.

43. Ahumada, G.G., and Saffitz, J.E. 1984. Fibronectin in the rat heart: a link between cardiac myocytes and collagen. J. Histochem. Cytochem. 32:383-388.

44. Casscells, W., Kimura, H., Sanches, J.A., Yu, Z.-X., and Ferrans, V.J. 1990. Immunohistochemical study of fibronectin in experimental myocardial infarction. Am. J. Pathol. 137:801-810.

45. Shekhonin, B.V., Guriev, S.B., Irgashev, S.B., and Koteliansky, V.E. 1990. Immunofluorescent identification of fibronectin and fibrinogen/fibrin in experimental myocardial infarction. J. Mol. Cell. Cardiol. 22:533-541.

46. Kishimoto, T.K., Jutila, M.A., and Butcher, E.C. 1990. Identification of a human peripheral lymph node homing receptor: a rapidly down-regu- 
lated adhesion molecule. Proc. Natl. Acad. Sci. USA. 87:2244-2248.

47. Moulder, K., Barton, A., and Weston, B. 1993. CD23-mediated homotypic cell adhesion: the role of proteolysis. Eur. J. Immunol. 23:2066-2071.

48. Itzhaky, D., Raz, N., and Hollander, N. 1998. The glycosylphosphatidylinositol-anchored form and the transmembrane form of CD58 are released from the cell surface upon antibody binding. Cell. Immunol. 187:151-157.

49. Jiang, Y., Zhu, J.F., Luscinskas, F.W., and Graves, D.T. 1994. MCP-1-stimulated monocyte attachment to laminin is mediated by beta 2 -integrins. Am. J. Physiol. 267:1112-1118.

50. Pacifici, R., et al. 1994. Ligand binding to monocyte $\alpha 5 \beta 1$ integrin activates the $\alpha 2 \beta 1$ receptor via the $\alpha 5$ subunit cytoplasmic domain and protein kinase C. J. Immunol. 153:2222-2233.

51. Shaw, L.M., and Mercurio, A.M. 1994. Regulation of cellular interactions with laminin by integrin cytoplasmic domains: the A and B structural variants of the alpha 6 beta 1 integrin differentially modulate the adhesive strength, morphology, and migration of macrophages. Mol. Biol. Cell. 5:679-690.
52. Penberthy, T.W., Jiang, Y., Luscinskas, F.W., and Graves, D.T. 1995. MCP1-stimulated monocytes preferentially utilize beta 2 -integrins to migrate on laminin and fibronectin. Am. J. Physiol. 269:60-68.

53. Yesner, L.M., Huh, H.Y., Pearce, S.F., and Silverstein, R.L. 1996. Regulation of monocyte CD36 and thrombospondin-1 expression by soluble mediators. Arterioscler. Thromb. Vasc. Biol. 16:1019-1025.

54. Sugahara, H., et al. 1994. Induction of programmed cell death in human hematopoietic cell lines by fibronectin via its interaction with very late antigen 5. J. Exp. Med. 179:1757-1766.

55. Li, J., Brown, L.F., Laham, R.J., Volk, R., and Simons, M. 1997. Macrophage-dependent regulation of syndecan gene expression. Circ. Res. 81:785-796.

56. Kluge, A., et al. 1997. Coordinate expression of the insulin-like growth factor system after microembolisation in porcine heart. Cardiovasc. Res. 33:324-331.

57. Randolph, G.J., et al. 1998. A physiological function for p-glycoprotein (MDR-1) during the migration of dendritic cells from skin via afferent lymphatic vessels. Proc. Natl. Acad. Sci. USA. 95:6924-6929. 